\title{
Effects of Plasma Treatment of Maize Seeds (No.2-Zhunuo) on the Biological Properties and Yield
}

\author{
Zhuwen Zhou ${ }^{1}$, Yanfen Huang' ${ }^{2}$, Guangqiang $\mathrm{Xu}^{3}$, Kong Bo ${ }^{1}$ \\ ${ }^{1}$ School of Physics and Electronic Science, Guizhou Education University, Guiyang, China \\ ${ }^{2}$ School of Biological Sciences, Guizhou Education University, Guiyang, China \\ ${ }^{3}$ Guiyang Baiyun Jinmandi Co., Ltd., Guiyang, China \\ Email: stevenzz@foxmail.com,gyhyf@126.com
}

How to cite this paper: Zhou, Z.W., Huang, Y.F., Xu, G.Q. and Bo, K. (2020) Effects of Plasma Treatment of Maize Seeds (No.2-Zhunuo) on the Biological Properties and Yield. Agricultural Sciences, 11, 439-447.

https://doi.org/10.4236/as.2020.114026

Received: March 16, 2019

Accepted: April 14, 2020

Published: April 17, 2020

Copyright $\odot 2020$ by author(s) and Scientific Research Publishing Inc. This work is licensed under the Creative Commons Attribution International License (CC BY 4.0).

http://creativecommons.org/licenses/by/4.0/

\begin{abstract}
The plasma seed processor was used to treat maize seeds (No.2-Zhunuo), and the effects of plasma treatment of the maize seeds on the biological properties and yield were studied by different doses $(250 \mathrm{~mA}-2000 \mathrm{~mA})$. The results showed that the effect of plasma treatment on the biological characters of maize was different, and the plant characters and yield of maize in the eight groups of plasma treatment were significantly higher than that of untreated (CK), especially the treatment current (dose) of $1500 \mathrm{~mA}, 1250 \mathrm{~mA}$, and 750 $\mathrm{mA}$, respectively, which had significant changes in the effect of maize plant traits. From the yield point of view, the top two are: plasma dose $1500 \mathrm{~mA}$, and $1250 \mathrm{~mA}$. The plasma doses of $750 \mathrm{~mA}, 1000 \mathrm{~mA}$, and $1500 \mathrm{~mA}$ were selected from the fruit number of maize. The disease resistance of treated maize is also better than that of untreated maize (CK). In a word, the yield, plant traits, and disease resistance of maize seeds can be improved to different extent by different doses of plasma.
\end{abstract}

\section{Keywords}

Plasma, Maize, Seed, Plant Traits, Yield

\section{Introduction}

The breeding of traditional crops, especially vegetables, adopts traditional breeding methods with long cycle and low efficiency. At present, physical technology has been widely used in agriculture, especially in the past decade, plasma treatment of seeds is a new technology, through its activation of seed endogen- 
ous substances, so that crops improve stress resistance, thereby increasing yield. Plasma processing seed technology, is the application of physical methods in agriculture, the cost is lower than the cost of biological agents and chemical agents to treat seeds, and do not pollute the environment. The application of plasma technology in agriculture has a broad prospect. We have used atmospheric pressure dielectric barrier plasma discharge at room temperature for some vegetables (tomato, eggplant, etc.), seed treatment [1]-[8] a decade ago, including the Chinese academy of sciences institute of physics for chili [9], lettuce [10], cucumber [11] and other crops to do plasma irradiation technology research, have achieved better results. These techniques mainly use atmospheric pressure dielectric barrier discharge plasma to produce high pressure outside the parallel plate, by adjusting different high pressure to achieve the treatment of different plasma dose of plant seeds, the related vegetable plants have better stress resistance and yield effect. In recent years, high-voltage arc ionization of air nitrogen and oxygen molecules has been used to produce plasma irradiation combined with alternating inductance, by adjusting the different current treatment of some seeds [12] [13] [14], but it has been found that the treatment group is not many, the current interval stage is large, the treatment dose is rough, and it is easy to lose some plant biological properties due to the small dose (small current change). In this study, the DL-2 plasma seed processor (Space Machine) was used to treat the seeds before crop sowing. This technology is to draw lessons from the physical effects of space plasma on seeds in space breeding. In the form of free fall, the seeds have been subjected to short-time light irradiation, inductive action and ozone sterilization to stimulate the potential of seeds, enhance the vigor of seeds and improve the robustness of seeds. After the seeds were treated, the crops had good characters, strong growth and disease resistance, and increased crop yield. Therefore, using atmospheric pressure plasma as a new type of seed treatment technology, the combined action of multiple factors will be beneficial to the improvement of varieties, and the technology is carried out at atmospheric pressure under normal temperature without vacuum equipment, easy to operate, low cost, and no damage to plant seed cells. Our research group treated solanaceae seeds (eggplant, tomato) with plasma treatment with different high pressures $(4760 \mathrm{~V}-6800 \mathrm{~V}, 4420 \mathrm{~V}-6800 \mathrm{~V})$ atmospheric pressure dielectric barrier discharge technology in the original study. The different plasma currents $(250 \mathrm{~mA}-2000 \mathrm{~mA})$ were used to treat maize seeds (No.2-Zhunuo), which were tested in nine groups, eight plasma treatment groups and one untreated group (CK), and the plasma treatment dose was subdivided to $250 \mathrm{~mA}$ to observe plant traits, disease resistance and yield changes in nine groups. Through mathematical statistical analysis, the optimal treatment dose of plasma seed treatment for maize yield can be selected. This research provides a new technical support for increasing the yield of maize and improving the benefit of agricultural production. 


\section{Materials and Methods}

\subsection{Test Sites and Materials}

The experiments were carried out in the Jinmandi Horticulture Science and Technology Test Field in Penglai Township, Baiyun District, Guiyang City, Guizhou Province, in March-July 2016, and in the Plasma Laboratory of the Institute of Physics and Electronic Science, Guizhou Education University. The plasma-to-seed treatment device uses a DL-2 plasma seed processor (Space Machine). The test material is No.2-Zhunuo of maize seed.

\subsection{Experiments Device}

In this test, corn seeds were treated using a Dalian Boshi plasma co., ltd. DL-2 plasma seed processor (Space Machine) device with power: $<1.2 \mathrm{kw}$; flow rate:="' >1500 kg/h; rated voltage: $220 \mathrm{v}$; frequency: $50 \mathrm{~Hz}$; current adjustment range: 0 - $3.5 \mathrm{~A}$; adjustable precision: $100 \mathrm{~mA}$. When processing, after power on, pull the lower part of the machine air protection switch to the on $(\mathrm{ON})$ position, the voltage indicator pointer swings to the right, showing the supply voltage, up press the plasma switch, the switch is bright, the circuit is on, the plasma emitter in the machine starts, the plasma indication is bright, then the light green light is reflected at the upper feed port of the machine. If the plasma radiant tube does not start, the plasma warning sounds, when the point presses the plasma start button (the point is not pressed, is pressed, pressed, pressed, put) until the start of the plasma radiant tube, warning to stop the call. After starting the preheating for $8 \mathrm{~min}$, press the strength switch up to adjust the desired current value by rotating the coarse adjustment and fine-tuning knob. The method of seed treatment is self-flowing, the seed does not stay in the machine, the seed is added from the top feed funnel, and the seed from the outlet must keep the seed flowing smoothly, keep the flowing speed of the seed, and the slow flow rate will affect the effect of seed treatment. Plasma treated seeds from pouring to receiving for once, and the number of treatments was 2 times.

\subsection{Test Methods}

\subsubsection{Plasma-Treated Seeds}

The seeds were tested in nine groups, 8 treatment groups and 1 control (CK) group. Maize seeds were treated with different currents by controlling the dose, the treatment currents were $250 \mathrm{~mA}, 500 \mathrm{~mA}, 750 \mathrm{~mA}, 1000 \mathrm{~mA}, 1250 \mathrm{~mA}, 1500$ $\mathrm{mA}, 1750 \mathrm{~mA}, 2000 \mathrm{~mA}$, these were compared with untreated seed (CK).

\subsubsection{Design of Test Field}

The total area of the test field was $1 \mathrm{mu}\left(667 \mathrm{~m}^{2}\right)$. Line spacing of $80 \mathrm{~cm}$, plant spacing of $50 \mathrm{~cm}, 2$ plants each time. Abdominal black membrane, hemp fertilizer compound fertilizer, leaf fertilizer (biological bacteria fertilizer) plus amoxicillin powder, the whole growth period topdressing 2 times, leaf 3 times. The overall growth is good, sprouting neatly, high and low about the same, the same 
fruit time, uniform size. The experiment recorded the yield, disease resistance and growth period (see Figure 1).

\section{Results and Analysis}

\subsection{Effect of Plasma Treatment by Different Doses (Current) on Maize Plant Traits and Yield}

\subsubsection{The Effect of Plasma on Maize Plant Height}

Increased $(30-40 \mathrm{~cm})$ in the eight groups treated with plasma compared with control (CK) from the survey (Table 1) of plant botanical traits in maize plants. The growth of treatment No.7 group was at least $30 \mathrm{~cm}$, while that of other treatment groups was $40 \mathrm{~cm}$ higher than that of untreated CK group.

\subsubsection{Effect of Plasma on Ear Height of Maize}

The ear heights of the maizes of eight groups treated by plasma were all $10 \mathrm{~cm}$ higher than that of the CK group.
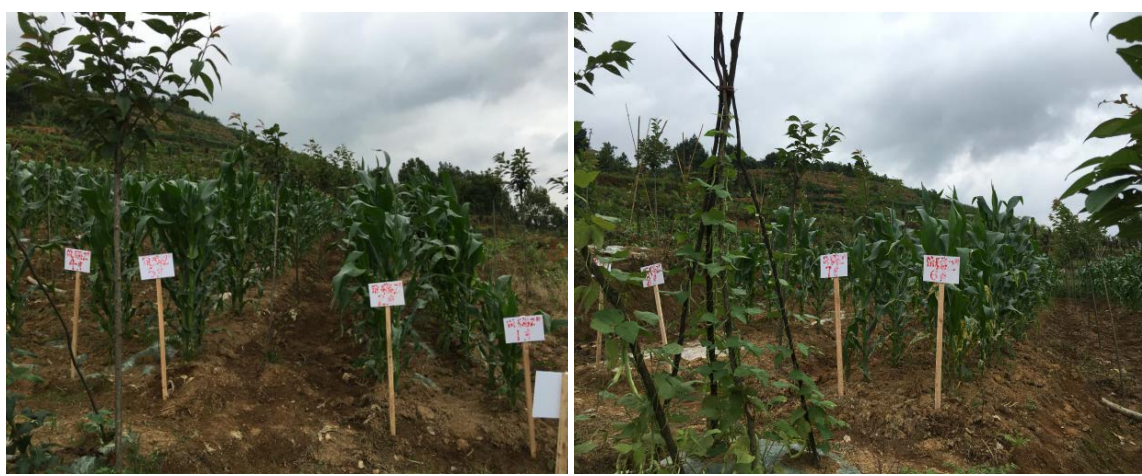

Figure 1. Using different doses of plasma to treat maize (8 treatment groups and $1 \mathrm{CK}$ group) growth in the field.

Table 1. Test record of effects of plasma treatment on maize.

\begin{tabular}{|c|c|c|c|c|c|c|c|c|c|c|c|}
\hline \multirow{2}{*}{$\begin{array}{c}\text { Group } \\
\text { number } \\
\text { No. }\end{array}$} & \multirow{2}{*}{$\begin{array}{c}\text { dose } \\
\begin{array}{c}\text { current } \\
/ \mathrm{mA}\end{array}\end{array}$} & \multicolumn{3}{|c|}{ plant traits } & \multicolumn{4}{|c|}{ yield traits } & \multicolumn{2}{|c|}{ disease/plant } & \multirow{2}{*}{$\begin{array}{c}\text { growth traits } \\
\text { growth } \\
\text { period/days }\end{array}$} \\
\hline & & $\begin{array}{l}\text { plant height } \\
\qquad / \mathrm{cm}\end{array}$ & $\begin{array}{c}\text { ear height } \\
/ \mathrm{cm}\end{array}$ & $\begin{array}{l}\text { number of } \\
\text { fruits per } \\
\text { plant/each }\end{array}$ & $\begin{array}{l}\text { single pod } \\
\text { length } / \mathrm{cm}\end{array}$ & $\begin{array}{c}\text { yield of per } \\
\text { plant } / \mathrm{kg}\end{array}$ & $\begin{array}{l}\text { initial } \\
\text { period }\end{array}$ & $\begin{array}{c}\text { spot } \\
\text { disease }\end{array}$ & $\begin{array}{l}\text { aphid } \\
\text { disease }\end{array}$ & $\begin{array}{l}\text { powdery bacterial } \\
\text { mildew wilt }\end{array}$ & \\
\hline 1 & 250 & $180-210$ & $110-120$ & 2 & $14-18$ & 0.8 & 38 & 1 & & & 120 \\
\hline 2 & 500 & $180-210$ & $110-120$ & 2 & $14-18$ & 0.6 & 38 & 1 & & & 120 \\
\hline 3 & 750 & $180-210$ & $110-120$ & 3 & $14-22$ & 0.8 & 38 & 1 & & & 120 \\
\hline 4 & 1000 & $180-210$ & $110-120$ & 2.5 & $14-22$ & 0.8 & 36 & 1 & & & 120 \\
\hline 5 & 1250 & $180-220$ & $110-120$ & 2 & $14-24$ & 0.9 & 38 & 1 & & & 120 \\
\hline 6 & 1500 & $170-210$ & $110-120$ & 3 & $14-24$ & 1 & 38 & 1 & & & 120 \\
\hline 7 & 1750 & $170-210$ & $110-120$ & 2 & $14-22$ & 0.8 & 38 & 1 & & & 120 \\
\hline 8 & 2000 & $180-210$ & $110-120$ & 2 & $14-22$ & 0.8 & 38 & 1 & & & 120 \\
\hline CK & 0 & $140-210$ & $100-120$ & 1 & $12-20$ & 0.5 & 38 & 2 & 1 & 1 & 120 \\
\hline
\end{tabular}




\subsubsection{Effect of Plasma on Number of Fruits per Plant of Maize}

The number of maize fruits per plant in each of the eight groups of plasma treatment increased by 1 - 2 than that in the control (CK). The maximum number of fruits per plant after treatment was No.3 group and No.6 group, there are 3 fruits per plant in them.

\subsubsection{Effect of Plasma on Single Pod Length of Maize}

The single pod length of the maize of eight groups treated with plasma increased to varying degrees $(2 \mathrm{~cm}-4 \mathrm{~cm})$ compared to control (CK), the longest growth of them was No.5, and No.6. group.

To sum up, after different doses of plasma treatment on maize seeds, the results of maize plant height, ear height, number of fruits per plant, single pod length and other plant traits have different degrees of influence, and each botanical character index is also different for different doses of plasma treatment, some indicators change significantly, some are not very obvious. All in all, compared with untreated CK, different doses of plasma treatment groups significantly promoted the growth and development of maize in the later stage of planting, especially the treatment group with significant changes in the influence of maize plant traits was No.6, No.5 and No.3 group.

\subsubsection{Effect of Plasma on Maize Yields}

Comparison of treated maize with untreated maize (CK) showed that the plasma treated eight groups produced higher yield than the control (CK) from Table 1, and the average yield of each of the eight treated groups increased $0.1 \mathrm{~kg}-0.5 \mathrm{~kg}$ than the CK. The first and second highest yields are: average yield $1 \mathrm{~kg}$ per plant of No.6 treatment group (plasma dose $1500 \mathrm{~mA}$ ), average $0.9 \mathrm{~kg}$ per plant of No. 5 treatment group (plasma dose $1250 \mathrm{~mA}$ ), average yield per plant increased by $50 \%$ and $44.44 \%$ respectively compared with CK. the minimum yield per plant also increased by $16.67 \%$. To sum up, different doses of plasma treatment can significantly promote the growth and development of maize in the later stage of planting, the effects of yield of maize seeds treated with appropriate dose (plasma current) are extremely significant. The plasma current treatment of $1500 \mathrm{~mA}$, and $1250 \mathrm{~mA}$ are better for maize yield index.

\subsection{Effect of Plasma Treatment by Different Doses (Current) on Disease Resistance of Maize}

From the maize disease (or pest) resistance in Table 1: Comparison of treated maize with untreated $(\mathrm{CK})$ found that except one or two plants in each group had small spot disease(white), no incidence of small spot disease, powdery mildew and bacterial wilt was found in all eight groups treated with plasma. However, there were 1 - 2 plants of maize in untreated CK group with spot disease, aphid disease and powdery mildew. In short, none of the plasma-treated maize exhibited strong disease resistance, at the same time, we found that plasmatreated maize was ineffective against small spot disease (white), no bacterial wilt 
was found in all groups (including CK).

\subsection{Mathematical Statistics of Plasma Treatment by Different Doses on Yields and Fruits Number of Maize}

\subsubsection{Mathematical Statistics of Maize Yield Trend Prediction}

The mathematical statistical analysis of maize yield per plant was carried out after different plasma dose treatments (see Figure 2: marked red dot represents real test data; black line represents yield prediction): maize yield prediction from regression trend line: After plasma current treatment, the relationship between the actual yield of each plant and the regression equation (yield prediction) basically accords with the Gaussian distribution law, this result rule is consistent with our previous research prediction [1] [3]-[6]. The appropriate dose range $(1000 \mathrm{~mA}-2000 \mathrm{~mA})$ has a large increase in maize yield after using plasma treatment seeds. Gaussian distribution prediction peak appears near $1500 \mathrm{~mA}$, and the yield trend prediction is basically consistent with the actual experimental data.

\subsubsection{Mathematical Statistics of Trend Prediction of Maize Fruit Number}

The mathematical statistical analysis of the number of fruits of each maize plant after different plasma dose treatment showed (see Figure 2: marked blue dot represents real test data; dark line represents fruit number prediction): the prediction of maize from the regression trend line: the relationship between the number of fruits per plant and plasma current treatment (regression equation) accords with the law of double-period average moving distribution, which indicates that there are two peaks in the number of fruits per maize plant. The first peak appears at $(750 \mathrm{~mA}-1000 \mathrm{~mA})$ and the second at $(1500 \mathrm{~mA}-1750 \mathrm{~mA})$. The test results demonstrated that the maize fruit numbers of the three treatment groups with selected plasma doses of $750 \mathrm{~mA}, 1500 \mathrm{~mA}$, and $1000 \mathrm{~mA}$ (No. 3, No. 6, and No. 4 groups) were the most for each plant. The trend prediction of the number of fruits per plant is basically consistent with the actual experimental data.

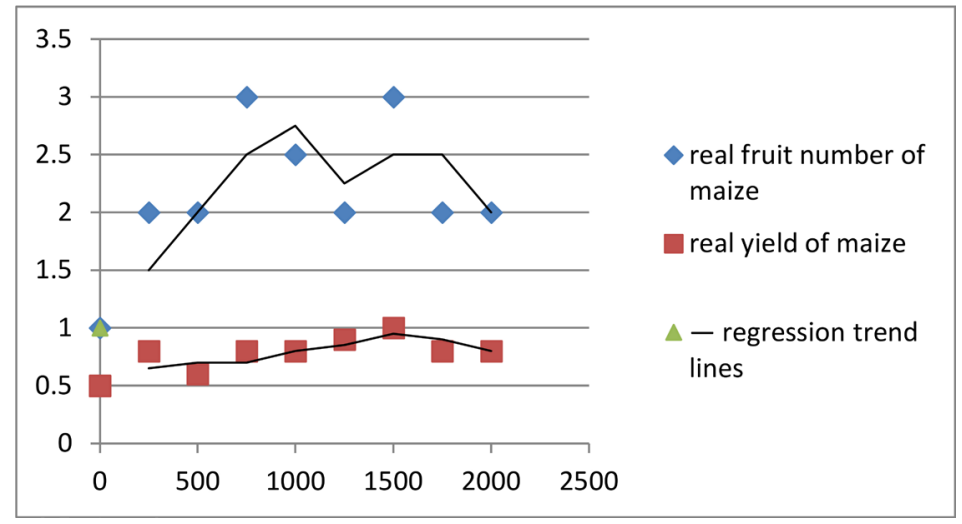

Figure 2. Trend prediction line and effect of different plasma doses on fruit number and yield of maize per plant. 


\section{Conclusions and Discussion}

Using the method of combining plasma irradiation with alternating inductance by high pressure arc ionization air nitrogen and oxygen molecules, it is undoubtedly of great economic and strategic significance to treat crop seeds, change their growth law, improve product quality and improve local crop yield by adjusting different current (dose) treatment plant seed technology. This kind of applied research has good prospects for solving some key technical problems in national economic and social development. It can provide a possible and effective way to increase the yield of more crops, and also build a technical platform for the improvement of traditional agricultural breeding techniques and the application of high and new technologies in agricultural breeding. Especially, the application of plasma technology to the development of agricultural science, biological science and other interdisciplinary disciplines has profound scientific significance.

We used a plasma seed processor to treat maize seeds (No.2-Zunuo), different doses $(250 \mathrm{~mA}-2000 \mathrm{~mA})$ were used to test the effects of plasma treatment on maize biological traits and yield. The experimental results showed that the seeds were treated with plasma irradiation combined with alternating inductance by high-voltage arc ionization of air nitrogen and oxygen molecules in order to induce physiological changes through investigation and analysis of its plant physiological changes in the external morphological characteristics, such as plant height, ear height, single pod length, the number of fruits per plant, as well as changes in seed stress resistance, disease resistance, the effect on yield. The results showed that different current (dose) plasma treatment had different effects on maize plant characters, and the different current (dose) plasma treatment was different.

The comparison between plasma treatment groups and CK group showed that all treatment groups significantly promoted the growth and development of maize after planting, especially the treatment current (dose) of $1500 \mathrm{~mA}, 1250 \mathrm{~mA}$, and $750 \mathrm{~mA}$, respectively, which had significant changes in the effect of maize plant traits. From the yield point of view, the top two are: plasma dose $1500 \mathrm{~mA}$, and $1250 \mathrm{~mA}$. The plasma doses of $750 \mathrm{~mA}, 1000 \mathrm{~mA}$, and $1500 \mathrm{~mA}$ were selected from the fruit number of maize. The regression trend prediction line of yield and result number of maize per plant is basically consistent with the experimental data. In summary, the effect of different doses of plasma treatment on maize biological traits was different. The maize plant traits and yield of eight groups treated with plasma were significantly higher than that of untreated group (CK), and the disease resistance of treated maize was also better than that of untreated (CK). Different doses of plasma treatment of maize seeds can improve seed yield, fruit number, and disease resistance to different degrees.

\section{Acknowledgements}

Project supported by Guizhou Province "first-class specialty physics" under 
Grant No. JGTH[2019]46, Guizhou Province "key support discipline theoretical physics" under Grant No. ZDXK[2015] 38, Guizhou Education University "key discipline plasma physics", and the National Natural Science Foundation of China under Grant No. 11464005.

\section{Conflicts of Interest}

The authors declare no conflicts of interest regarding the publication of this paper.

\section{References}

[1] Zhou, Z.W., Huang, Y.F., Yang, S.Z. and Deng, M.S. (2010) Effects of Atmospheric Pressure Plasma Treatment on Growth, Development, Yield and Quality of Tomato. Anhui Agricultural Science, 38, 1085-1088.

[2] Zhou, Z.W., Huang, Y.F., Yang, S.Z. and Deng, M.S. (2010) Effect of Atmospheric Pressure Plasma on Plant Growth and Yield of Eggplant. Chinese Vegetables, No. 4, 62-66.

[3] Zhou, Z.W., Huang, Y.F., Deng, M.S. and Yang, Size. (2009) Effects of Atmospheric Pressure Plasma Treatment on Yield and Quality of Eggplant of No.2-Qianqie Seed. Modern Agricultural Technology, No. 19, 94-96.

[4] Zhou, Z.W., Huang, Y.F., Yang, S.Z. and Deng, M.S. (2009) Effects of Plasma Treatment on Plant Growth, Development and Yield Quality of No.10-Hongza Seed. Guizhou Agricultural Science, 37, 58-61.

[5] Zhou, Z.W., Huang, Y.F., Yang, S.Z. and Chen, W. (2011) Introduction of a New Atmospheric Pressure Plasma Device and Application on Tomato Seeds. Agricultural Sciences, 2, 23-27. https://doi.org/10.4236/as.2011.21004

[6] Zhou, Z.W., Huang, Y.F., Chen, W. and Yang, S.Z. (2011) A New Atmospheric Pressure Plasma Equipment and Its Application in Eggplant Seeds. Guizhou Agricultural Science, 39, 61-65.

[7] Huang, Y.F. and Zhou, Z.W. (2011) Effect of Atmospheric Pressure Plasma Technology on Eggplant. Seeds, 29, 73-75.

[8] Zhou, Z.W., Yang, S.Z., Huang, Y.F. and Chen, W. (2010) Effects of Atmospheric Pressure Plasma on Growth and Development of Tomato. Proceedings of International Conference on Agricultural Sciences and Engineering, Macau, 10-11 September 2010, 55-57.

[9] Chen, G.L., Fan, S.H. and Yang, S.Z. (2005) A Novel Atmospheric Pressure Plasma Fluidized Bed and Its Application in Mutation of Plant Seed. China Physics Letter, 22, 1980-1983. https://doi.org/10.1088/0256-307X/22/8/044

[10] Wang, M., Chen, Q.Y. and Yang, S.Z. (2007) Effects of Atmospheric Pressure Plasma Treatment on Seed Germination and Growth of Lettuce. North China Journal of Agriculture, 22, 108-113. https://doi.org/10.1016/S1671-2927(07)60023-6

[11] Wang, M., Yang, S.Z. and Chen, Q.Y. (2007) Effects of Atmospheric Pressure Plasma Treatment on Seed Germination and Seedling Growth of Cucumber. Journal of Agricultural Engineering, 23, 195-200.

[12] Fang, X.Q., Bian, S.F. and Xu, K.Z. (2004) Effects of Plasma Treatment on Biological Properties and Yield of Maize Seeds. Journal of Maize sciences, 12, 60-61. 
[13] Ma, X.L., Qu, Q.H. and Liu, F. (2010) Effect of Plasma Seed Processing Machine on Maize. Modern agriculture, No. 5, 15-16.

[14] Geng, S.J., Geng, L.Z. and Chen, Z.G. (2014) Effect of Plasma Seed Processing Machine on Maize. Modern agriculture, No. 2, 28-29. 